\title{
Editorial for the CEAS Aeronautical Journal special issue on research in air transportation
}

\author{
Hartmut Fricke ${ }^{1} \cdot$ Dirk Schäfer ${ }^{2}$
}

Published online: 27 May 2020

(c) The Author(s) 2020

Rooted in the long-standing collaboration agreement with the Federal Aviation Administration (FAA), EUROCONTROL has been organizing a twin-series of scientific conferences since the late 1990's. The first US-Europe Air Traffic Management (ATM) Research and Development Seminar, or ATM Seminar for short, took place in Saclay, France, in 1997. The seminar has since matured into a recognized high-quality conference, with attendance from top-researchers from many countries; all papers and presentations are available for download on the conference website which to date hosts more than 800 scientific articles. The ATM Seminar takes place every two years, in odd years to be precise and in locations that alternate between the United States of America and Europe (the last seminar was set in Vienna in June 2019).

Alternating with and closely related to the ATM Seminar is the International Conference for Research in Air Transportation (ICRAT) which was introduced in 2004. Likewise, ICRAT is jointly organized by the FAA and EUROCONTROL. ICRAT specifically encourages young researchers to present their work and provides the space for constructive feedback from the research audience in a very intensive and direct way. As such, ICRAT offers aside the technical sessions a PhD symposium track. The ICRAT paper selection process is based on a triple peer-review through recognized experts forming the Programme Committee. The conference outcome is listed in the Scopus publication index.

The 8th ICRAT conference, to which this Special Issue is dedicated, was hosted by the Technical University of Catalonia and took place in Castelldefels, near Barcelona. Attended by more than 100 researchers, 66 papers were presented in a number of technical tracks. Awards were presented to the

\footnotetext{
Hartmut Fricke

hartmut.fricke@tu-dresden.de

1 Dresden Technical University, Dresden, Germany

2 EUROCONTROL, Brétigny-sur-Orge, France
}

best paper in each track, selected by members of the programme committee.

The authors of the best papers were subsequently invited to submit their paper to the CEAS Aeronautical Journal, with a view to producing a Special Edition entirely dedicated to ICRAT 2018. As Guest Editors of this CEAS Journal Special Issue, we are delighted to offer the reader, as a result, six selected papers tackling novel and highly relevant aspects of the worldwide ongoing Air Transport System modernisation. For highly complex airspaces, a powerful method to deconflict aircraft using cooperative strategies is presented in the first paper of Degas, Rantrua, Kaddoum, Gleizes and Adreit [1]. The second paper by Lindner, Rosenow and Fricke [2] as well as third paper by Rosenow, Strunck and Fricke [3] deal with optimizing aircraft trajectories online-so during flight_-in all four dimensions. The concept excels current predictive techniques as it continuously considers altering environmental conditions of flight, triggering trajectory updates if needed. Along the rapidly digitizing transformation of the transport system in general, the fourth paper by García-Albertos, Cantú Ros and Herranz [4] investigates into smart logics to use mobile phone passenger data to assess the system performance from the customer perspective. Its aim is to leverage the full potential of minimizing travel times from door to door. The fifth paper by Dalmau, Prats, Ramonjoan and Soley [5] focuses on the ecological effects of air transport by providing insight into the complexity existing to precisely assess fuel consumption for single flight operations from the system's perspective. It hints to the still existing data access shortages nowadays, hampering research and investigation related to technical system performance assessment. The last paper by Tereshchenko and Hansen [6] investigates into observed responses made by airlines by inferring utility functions of different route options with respect to flight time and arrival delay using a finite mixture latent class choice model.

The editors would like to thank all authors for their contributions to this CEAS Aeronautical Journal Special Issue. 
All over, we are more than convinced that this Special Issue will offer a remarkable, well selected insight into current air transportation research activities you should not miss. Enjoy your reading experience.

\section{Acknowledgements Open Access funding provided by Projekt DEAL.}

Open Access This article is licensed under a Creative Commons Attribution 4.0 International License, which permits use, sharing, adaptation, distribution and reproduction in any medium or format, as long as you give appropriate credit to the original author(s) and the source, provide a link to the Creative Commons licence, and indicate if changes were made. The images or other third party material in this article are included in the article's Creative Commons licence, unless indicated otherwise in a credit line to the material. If material is not included in the article's Creative Commons licence and your intended use is not permitted by statutory regulation or exceeds the permitted use, you will need to obtain permission directly from the copyright holder. To view a copy of this licence, visit http://creativecommons.org/licenses/by/4.0/.

\section{References}

1. Degas, A., Rantrua, A., Kaddoum, E., et al.: Dynamic collision avoidance using local cooperative airplanes decisions. CEAS Aeronaut. J. (2019). https://doi.org/10.1007/s13272-019-00400-6
2. Lindner, M., Rosenow, J., Fricke, H.: Aircraft trajectory optimization with dynamic input variables. CEAS Aeronaut. J. (2019). https://doi.org/10.1007/s13272-019-00430-0

3. Rosenow, J., Strunck, D., Fricke, H.: Trajectory optimization in daily operations. CEAS Aeronaut. J. (2019). https://doi. org/10.1007/s13272-019-00429-7

4. García-Albertos, P., Cantú Ros, O.G., Herranz, R.: Analyzing door-to-door travel times through mobile phone data. CEAS Aeronaut. J. (2019). https://doi.org/10.1007/s13272-019-00432-y

5. Dalmau, R., Prats, X., Ramonjoan, A., et al.: Estimating fuel consumption from radar tracks: a validation exercise using FDR and radar tracks from descent trajectories. CEAS Aeronaut. J. (2020). https://doi.org/10.1007/s13272-020-00441-2

6. Tereshchenko, I., Hansen, M.: Relative trajectory cost estimation for CTOP applications using multivariate nonparametric finite mixture logit. CEAS Aeronaut. J. (2020). https://doi.org/10.1007/ s13272-020-00442-1

Publisher's Note Springer Nature remains neutral with regard to jurisdictional claims in published maps and institutional affiliations. 